\title{
Advancement in Food Technologies-Food Chemistry Congress 2020!
}

\author{
Rammal L* \\ Diet Center Owner \& CEO, Lebanon
}

\section{Conference Announcement}

We feel honoured to welcome you to "Food Chemistry Congress 2020". The congress is scheduled to happen on August $24-25,2020$ at the beautiful city of London, UK. This Food Chemistry Congress 2020 will give you an exemplary experience and enormous ideas in the research field.

Food Chemistry Congress 2020 provides you a great networking with peer network. Also, comprise, $10^{+}$Keynote Speaker Session, 50+ speaker faculty over 2 full days sharing evidence Based, $5^{+}$Workshops, 13 Interactive sessions, Mixture of Health care units and Academia Delegates, Networking provide a dedicated forum for the advancement, execution, and exchange of information about Food Chemistry \& Nutrition. Professionals giving a chief specialized gathering to detailing and finding out about the most recent new era advancements created over the span of time alongside examining their applications. Generally acclaimed speakers, the most recent techniques, methodologies, and the most breakthrough updates in Nutrition are indications of this online meeting/webinar/podcast.

The perspective of the webinar of Food Chemistry Congress 2020 is to establish research works for people to understand how the technologies in Food get advanced and how the field get emerged in recent years. It also pampers Young Researchers to have emerging future and a chance to be the member if this great online event.

The sessions to be discussed in the conference includeAdvancements in Food Chemistry, Food Processing and Technologies, Nanotechnology in Food Packaging and Food Safety, Chemical Composition of Food, Food Preservatives and Additives, Food Waste Recycling and many more.

The participants who are expected to attend the conference are Eminent Scientific Professionals in FoodNutrition and Food Chemistry, Faculty (Professors, Associate Professors, Asst. Professors), Dietetics, and Food Chemistry offering Colleges \& Training Institutes, Food and Nutrition Associations and Societies, Food Business Entrepreneurs, Manufacturing Food products Companies, Food \& Drug Companies, Students, PhD Scholars, Graduates and Post Graduates, Directors, CEO's of Companies and organizations. Association, Association presidents and professionals, Noble laureates in Health Care and Medicine, Bio instruments Professionals, Bio-informatics Professionals, Research Institutes and members, CRO and DATA management Companies, Data Management Companies.

\section{*Address for Correspondence: Rammal L, Diet Center Owner \& CEO, Lebanon, Tel: +009617769521; \\ E-mail: info@linarammal.com}

Copyright: (c) 2020 Rammal L, et al. This is an open-access article distributed under the terms of the creative commons attribution license which permits unrestricted use, distribution and reproduction in any medium, provided the original author and source are credited.

Received 06 Nov, 2019; Accepted 16 June, 2020; Published 23 June, 2020
The people who have missed attending the past Food Chemistry Conferencesare most welcome to present your research ideas inFood Chemistry Congress 2020. This conference will help you to improve networking with the eminent people in the Food \& Nutrition field.

Our organizing committee members would like to invite all the potential people to participate in the Food Chemistry Congress2020online to develop and enhance the field of Nutrition and Food Chemistry Technologies.

Make your footprint in the Food Chemistry Congress 2020 to explore the Exploring Recent Advancement in Food Chemistry and Technology.

\section{Some of the Glimpses of Past Conferences:}
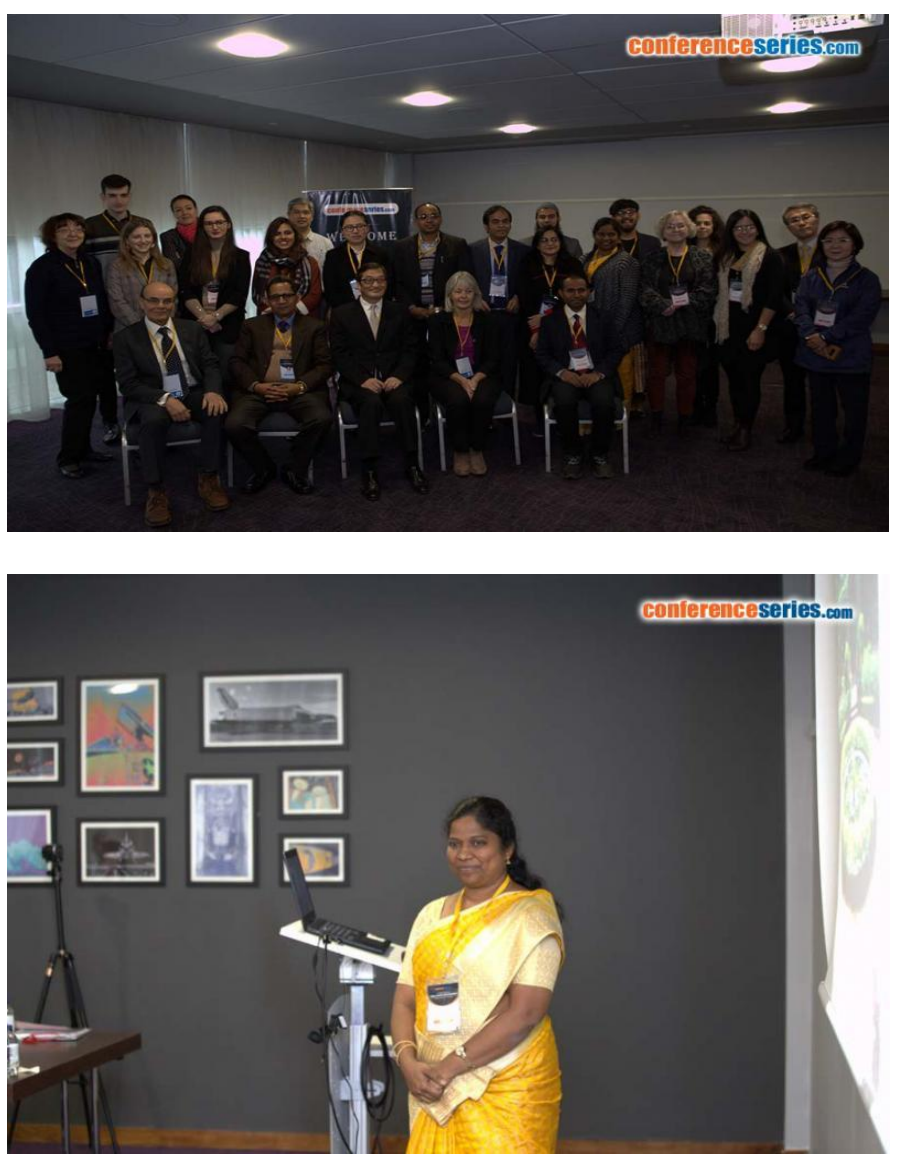


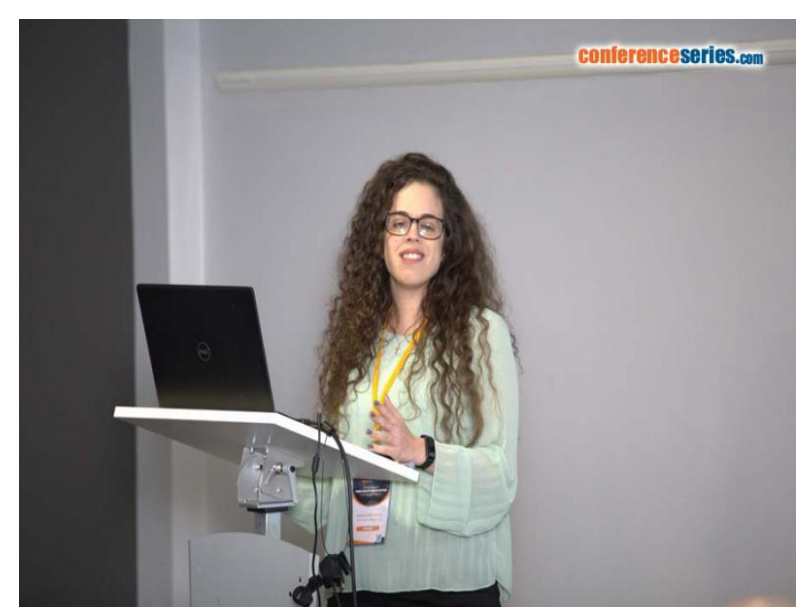

How to cite this article: Kha Muhammad Rizwan Ishaq, Muthalagu Poochellam, Anam Yousaf, Bashir Farhan and Hannan Kieran, et al. "Identification and Treatment of Hypovitaminosis-D among in-patients setting of Cavan General Hospital, Ireland and its implication on different health perspectives and quality of life." Vitam Miner 09 (2020): e158. doi:10.37421/VTE.2020.9. e155. 